\title{
Development of Dentin Bonding Systems from Past to Present
}

\author{
(i) Mağrur KAZAK1, id Nazmiye DÖNMEZ²
}

1Bahçeşehir University, School of Dental Medicine, Department of Restorative Dentistry, İstanbul, Turkey

2Bezmialem Vakif University, Faculty of Dentistry, Department of Restorative Dentistry, İstanbul, Turkey

\begin{abstract}
Providing a stable and long lasting bonding to the tooth is an ideal requirement for the success of restorations. Therefore dentin bonding systems are important clinical contributions to recent composite technology. The first, second and third generations are classified under historical title while; etch\&rinse, self-etch and multi-mode adhesives are classified under the title of current clinical practice procedures strategies. The preferred properties of adhesive systems are biocompatibility with dental tissues, improved bond strength to dental tissues, and better resistance to chewing stresses. In recent years, the success rate of restorative treatment of teeth that have suffered from caries or loss of supporting tissue has increased considerably due to the developments in dentin donding systems.
\end{abstract}

Keywords: Dental enamel, dentin, dentin-bonding agents, dental adhesives, classification

\section{Introduction}

Adhesive systems are one of the most important factors affecting the success of restorative dentistry. First, adhesive dentistry was born out of the idea of Buonocore (1) to provide retention with micromechanical retention by roughening the enamel tissue with $85 \%$ phosphoric acid for 30 seconds. At the end of the 1970s, dentin bonding systems have made a major breakthrough with the introduction of the view that phosphoric acid can be applied on dentin tissue.The mechanism of adhesion of the dentin bonding systems used today to the tissues of the teeth is defined as a natural micromechanical adhesion with the penetration of adhesive resin to collagen which is exposed on the surface of the dentin roughened with acid. "Hybrid Layer" (2) in other words' interdiffusion layer' (3) is one of the basic mechanisms of adhesion. The terms and their meanings used to understand adhesion mechanism are very important.

\section{Adhesion}

The word "adhesion" (attachment) originates from the Latin word "adhaere". The adhesion of the two materials can be expressed as the contact of their interfaces with each other decisively. In adhesive terminology, adhesion is the bonding of one substance to another. This substance or surface is called "adherent", whereas the substance that creates the adhesion is called "adhesive". Three different mechanisms of adhesion are mentioned in the dentistry literature (4).

Chemical Adhesion: It is based on primary bond values (joining forces) such as covalent, ionic and metallic bonds. Chemical adhesion is the limited and weak bonding between atoms of surfaces which are different in structure (5).

Physical Adhesion: It is a weak type of bonding between surfaces which are different in structure, resulting fromVan der Walls forces and hydrogen bonds (5). 
Mechanical Adhesion: At the microscopic level, it is based on the penetration of a material into a different material. It is the strong locking that occurs between rough surfaces. In this strong locking, both geometric and rheological factors are engaged. Mechanical adhesion caused by surface roughness or microscopic porosity is an example of geometric factors, while the flow of the material around a bulge due to its fluid properties and its hanging on with shrinkage is an example of rheological factors (5).

In order to achieve adhesion effectively, the distance between adhesive and adherent must be minimal. It is possible for the adhesive to wet the surface when the free surface energy of the adherent is greater than the surface tension energy of adhesive. It is possible for a liquid to wet a surface when the angle between the surface and the liquid is close to zero degrees. In other words, if this angle is zero degrees, it is assumed that the adhesive completely wets the relevant surface.

These basic criteria, which are necessary to establish adhesion forces, are realized by acid application. The enamel and dentin tissues are subjected to acidification process and the previously mentioned criteria of adhesion are fulfilled. After the acid process is applied, the enamel and dentin surfaces are ready for first primer and then bonding agent applications. The area between the surfaces of these tissues and the surface on which the binding agent comes into contact is called the "interface", and this is where adhesion occurs.

\section{Important Terms Related to Adhesive Systems}

\section{Hybrid Layer}

After demineralization of the dentin surface by acidification process, collagen fibrils are released. Low-viscosity monomers fill the nano-cavities formed by demineralized hydroxyapatite crystals by penetrating into this region and surround the collagen. By polymerization process, adhesive resin is micromechanically bonded with dentin collagens. This resin-reinforced, acid-resistant layer is called "hybrid layer" (2). The main binding mechanism of adhesive restorative materials is based on the formation of the hybrid layer. The hybrid layer was first identified by Nakabayashi (2) in 1982 and expressed as a mixture of demineralized dentin compounds and polymerized adhesive resin at molecular-level.

\section{Resin Tags}

Adhesive resin extensions directed/flowing into open dentin tubules are called "resin tags" (6). The structure of these tags varies according to the application technique of acid, the thickness of the remaining dentin, the surface moisture and structure of the dentin. When the peritubular dentin is removed from the tubule wall by the acidification process, the adhesive resin diffuses into the demineralized matrix. After polymerization, resin tags are attached to the tubule wall by hybridization. "Submicron resin tags" are formed when the adhesive resin infiltrates the lateral tubule arms (7).

\section{Primer}

Primers are used as binding-enhancing agents and consist of hydrophilic monomers dissolved in organic solvents such as water, acetone and ethanol. They facilitate the infiltration of the monomer into the nano cavities in the resulting collagen network by replacing with water on the dentin surface and in the moist collagen network with their volatile characters (7). Applying primers on the dentin tissue which are acidified restores the shrunken collagen, allowing the resin to be better diffused into the dentin tissue. Thus, the quality and binding resistance of the hybrid layer is increased (8). In other words, primers harmonize hydrophilic dentin with hydrophobic adhesive resin. The primer-applied surface contains non-polymerized bindingenhancing molecules. These molecules polymerize together with the bonding agent applied to the demineralized surface. The ideal binding is completed after polymer intertwins with collagen fibrils and hydroxyapatite crystals and wraps them.

\section{Adhesive Resin}

Adhesive resins, also called bonding agents, have both hydrophilic and hydrophobic properties. These systems consist of hydrophobic monomers such as bisphenol A-glycidyl methacrylate (BisGMA) and urethane dimethacrylate (UDMA), viscosity regulators such as triethylene glycol dimethacrylate (TEGDMA) and wetting agents such as hydroxyethyl methacrylate (HEMA) (2). Hydrophobic monomers interact with restorative materials and copolymerize, while hydrophilic monomers increase the wettability of dental hard tissues (9). The biggest difference between hydrophilic and hydrophobic adhesives is the chemistry of their monomers and solvents. The most commonly used monomers in adhesive systems are HEMA and Bis-GMA. HEMA can be fully mixed in water and acts as a polymerizable wetting agent perfect for dental adhesives. Bis-GMA, on the other hand, is much more hydrophobic and, when polymerized, absorbs only about $3 \%$ water by weight into its structure (10). The mixture of the two is like an intermediate and serves as a useful adhesive for dental hard tissues. The chemical composition of adhesive systems also includes initiators, inhibitors or stabilizers, solvents and, in some cases, inorganic fillers (11). In 1982, Nakabayashi (12) was the first to demonstrate the formation of a true hybrid layer, and named this new biocomposite structure, the hybrid layer. This layer has been considered the main binding mechanism of binding agents. The most important tasks of binding agents are to fill the nano cavities formed in collagen after acidification, to ensure the formation of resin tags by infiltrating into the dentin tubules, to provide the formation of a uniform and stable hybrid layer (13). Proper wetting of the surface with the binding agent is based on proper selection ofprimer and ideally application of the primer. The hybrid layer obtained after the application of primer is polymerized together with the bonding agent (7).

\section{Development, Use and Classification of Dentin Adhesive Systems}

\section{Dentin Adhesives}

They are intermediate materials that can be connected with both dentin tissue and composite resin and are developed to help ensure the connection between dentin tissue and composite resin surfaces and the retention of restoration, to prevent microleakage and to prevent dentin sensitivity that may occur after restoration by covering dentin tubules (13). 
Adhesive systems consist of dentin conditioner, dentin primer, and dentin adhesives applied at different stages. There are also systems where the primer and conditioner are combined or primer and adhesive are combined (14).

\section{Properties of Dentin Adhesives}

Enamel/dentin bonding systems used to perform adhesive bonding are today called "adhesive systems". Properties sought in adhesive systems:

- Prevention of microleakage and secondary caries,

- To be able to withstand stresses caused by polymerization shrinkage and under chewing forces,

- Micromechanical and chemical bonding to enamel and dentin tissue,

- To be able to connect to enamel and dentin tissue as well as to be able to connect to metal and porcelain,

- Easy application on moist surfaces (Wet-bonding),

- Easy clinical application without technical precision,

- Preventing post operative sensitivity by closing all or part of the dentin channels,

- Being biologically acceptable (15).

As a result of the tissue removal procedures performed during cavity preparation by using milling tools, the dentine surface is covered by a smear layer consisting of blood, saliva, bacteria, hydroxyapatite crystals and denatured collagen (16). The smear layer, which protects the dentin and pulp tissue against irritation, is about $0.5-2 \mu \mathrm{m}$ thick and is porous and amorphous in appearance. The different thickness of the smear layer also causes differences in the permeability of dentin tissue. Dentin tubule mouths are clogged with smear plugs, which reach a depth of 1 to $10 \mu \mathrm{m}$ of tubules. These smear plugs are a continuation of the smear layer consisting of fragmented and denatured hydroxyapatite (16). There are various opinions about the removal or modification of this layer, which is effective in adhesion binding. Some of the researchers have argued that the smear layer creates a barrier for rnicroorganisms to reach the pulp, and have reported that with removal of this layer, dentin permeability will increase 5-10 times. Another group of researchers have shown that the smear layer is a shelter for bacteria to settle and multiply (12).

\section{Classification of Dentin Adhesives}

Over the years, dentin adhesive systems have been classified numerous times by authorities. Researchers have made this classification based on the stages of clinical practice and modern adhesive strategies, sometimes through generation.

With changes in adhesive dentistry, adhesive systems have developed from the stage where no acid is applied to totaletch (4. and 5. generation) and later self-etch (SE) (6., 7. and 8. generation) (17). Each generation has tried to minimize procedure steps, allowing clinicians to finish restorations in less time with less technical precision. In addition, improved chemical structures of dentin adhesives have resulted in better bonding (18).

Dentin adhesives can be classified in three main groups (Table 1) $(19-22)$ :

The first group is called the historical classification. It consists of $1^{\text {st. }}$, 2. and 3. generation dentin adhesive systems.

Second group: Dentin adhesives are classified according to their effect on the smear layer. They can be examined in 4 groups: The adhesive systems which are applied on the smear layer, modify the smear layer, remove the smear layer completely and dissolve the smear layer (22).

The third group is the current classification, in other words, the classification of dentin adhesives according to the type of application in the clinic:

1. Etch\&rinse (ER)

a-3-stage

b-2-stage

1. Self-etch

a-2) Stage

b-1) Stage

1. Universal (Multi-mode) (17).

According to Historical Classification;

First Generation Adhesive Systems (Adhesive Systems Applied on Smear Layer)

In 1955, Buonocore demonstrated that glycerophosphoric acid dimethacrylate can bind with hydrochloric acid to the surface

Table 1. Classification of dentin adhesives

Chronological classification

1. Historical classification

First generation

Second generation

Third generation

2. Classification according to their effect on smear layer

-Smear tabakasının üzerine uygulanan

-Modifying the smear layer

-Completely removes the smear layer

-Dissolves the smear layer

3. Current classification (according to clinical application types) Etch\&rinse (ER) adhesives

Three-stage etch \& rinse (ER) adhesives (Fourth generation)

Two-stage etch \& rinse (ER) adhesives (Fifth generation)Self-etch adezivler

Two-component self-etch adhesives (Sixth generation)

One-component and one-stage self-etch adhesives (All-in-one)

Eighth generation

Universal (Multi-mode) 
of roughened enamel (1). Later, Bowen and Rodriguez theorized that N-phenyl glycine glycidyl methacrylate (NPG-GMA) forms a chemical bond with dentin (21). As a result of these studies, in 1962, manufacturers produced NPG-GMA origin dentin bonding agents, also called first generation dentin adhesives, but dentin bondings in this generation had a hydrophobic structure, so their attachment strength to dental tissues was low (2-6 MPa) (23).

\section{Second Generation Adhesive Systems (Adhesive Systems Applied on Smear Layer)}

These systems, which are halophosphate esters of resin monomers such as Bis-GMA or HEMA, were developed in the early 1980s. The second generation adhesive systems did not have sufficient binding strength to resist the polymerization shrinkage of composite resin $(1-10 \mathrm{MPa})$. Although the first and second generation adhesive systems were developed to bind to the inorganic structure of the dentin, the desired clinical success was not achieved (23).

\section{Third Generation Adhesive Systems (Adhesive Systems that Modify the Smear Layer)}

In this system, the smear layer is modified and the penetration of the resin monomer to the dentine is provided (20). The idea of roughening dentin tissue with phosphoric acid before this bonding agent containing phosphonate ester is applied was put forward by Fusayama et al. (23). However, due to the hydrophobic nature of the bonding agent, the desired success in terms of binding strength was not achieved again (23).

\section{Fourth Generation Adhesive Systems (Adhesive Systems that Completely Eliminate the Smear Layer)}

The fourth generation dentin bonding systems are the first to completely eliminate the smear layer and are recognized as the gold standard. They are still used in current clinical applications (20). In these systems, which reduce dentin permeability and eliminate the smear layer, which is considered to be a diffusion barrier, orthophosphoric acid is applied to both enamel and dentin tissue at the same time (Total-etch) at a concentration of $30-40 \%$. Etch \& rinse adhesive systems can be either three-stage or two-stage.

\section{Fourth Generation: Three-stage Etch\&Rinse Adhesive Systems}

These adhesive systems with proven binding strength values toenamel (20-50 MPa) and dentin (13-80 MPa) are applied in three stages following each other.

$1^{\text {st }}$ Stage: Changing the surface conditions of enamel and dentin (roughening with acid),

$2^{\text {nd }}$ Stage: Application of adhesion enhancing agents (application of primer),

$3^{\text {rd }}$ Stage: Infiltration of bonding agent to demineralized enamel/ dentin surface.

\section{$1^{\text {st }}$ Stage: Change Of Enamel/Dentin Surface Conditions}

The reason for changing the enamel/dentin surface conditions is to create a suitable enamel/dentin surface that can provide chemical and micro-mechanical bonding of bonding agents. At this stage, different concentrations of phosphoric acids are applied to the enamel and dentin tissue simultaneously (Total-etch) for a certain period of time (minimum=15 sec, maximum $=30 \mathrm{sec}$ ) and then the acid is washed away from the tooth surface as far as the duration in which acid is applied. As a result of acid roughening process, the smear layer in the enamel is removed and the aprismatic layer is removed about $10 \mu \mathrm{m}$ from the surface of the enamel.By acidification, a large number of microscopic indentations and protrusions are created at a depth of approximately $5-50 \mu \mathrm{m}$, increasing the surface area and increasing the critical surface tension value (CST) of the enamel tissue to 72 dynes $/ \mathrm{cm}$. All these factors provide an alignment between composite resin and cavity wall, increasing the retention of restoration and greatly reducing edge leaks.

Generally, 37\% orthophosphoric acid is used for roughening with acid. Silverstone et al. (24) showed with Scanning Electron Micrograph (SEM) studies that three types of roughening occur in orthophosphoric acid-roughened enamel tissue, depending on the concentration of the acid and the duration of application. In the first type of roughening, the inner parts of the mine prisms are dissolved and removed, resulting in the appearance of honeycomb. In the second type of roughening, the periphery of the mine prisms is dissolved and removed, resulting in a paving stone image. The third type of roughening is a dissolution that does not conform to the morphology of the prisms, and a more faint appearance is observed (23). Hydroxyapatite crystals show a regular distribution in enamel tissue, while in dentin tissue they are randomly distributed in organic matrix. In addition, the hydroxyapatite crystals in the dentin tissue are smaller than the crystals in the enamel tissue and contain less calcium and carbonate. For this reason; the mineralization of the dentine tissue is less than the enamel tissue, more than the cement tissue and bone.

Dentin has a large number of tubules/ducts filled with fluid. These begin from the pulp tissue and pass through the dentine tissue, reaching the mine-dentin border. The tubules are coiled with well mineralized peritubular dentin. Among the tubules is intertubular dentin, whose mineralization is less than peritubular dentin. The liquid inside the tubules is pushed from the pulp tissue towards the outer surfaces with a approximately 25-30 $\mathrm{mmHg}(34-40 \mathrm{~cm}$ water pressure). This is why dentin tissue is always moist (23). There is a continuous fluid exchange in the dentin tissue which is dynamic. The protein ratio of dentin tissue is high and therefore the critical surface tension value (CST, 44.8 dynes $/ \mathrm{cm}$ ) is lower than enamel tissue. The low surface energy of the dentin tissue also reduces the wettability of this tissue and makes bonding difficult.

The main factors involved in dentin adhesion are the content of dentin tissue (density, diameter, peritubular and intertubular dentin ratio), dentin thickness and structure (demineralized/ sclerotic), smear layer and age. The diameter and number of dentin tubules in deep or superficial cavities affect the adhesion strength.The tubules make up $28 \%$ of the dentin near the pulp by volume and $4 \%$ of the dentin at the enamel-dentin border. 
Furthermore, the number of tubules near the pulp (45,000 in $\left.\mathrm{mm}^{2}\right)$ and its diameter $(25 \mu \mathrm{m})$ is greater than the number of tubules at the enamel-dentine border $\left(20,000\right.$ in $\left.\mathrm{mm}^{2}\right)$ and its diameter $(0.8 \mu \mathrm{m})$. Accordingly, adhesive bonding strength is lower on deep dentin surfaces closer to pulp tissue (23).

By applying acid to dentin tissue, smear layer is removed as a result of removal of tissues using milling tools or cutting hand tools during cavity preparation, smear plugs (plug) are eliminated, there is a flow of fluid from the dentin tubules towards the dentin surface and the permeability of dentin tissue increases 5-20 times.In addition, a drop in the critical surface tension value of dentin tissue $(44.8$ dynes $/ \mathrm{cm})$ is observed with acidification (29.48 dynes/cm) (23). This decrease in the value of CST negatively affects adhesion. The purpose of the primer applied in the second phase of adhesive systems is to increase this value.

\section{$2^{\text {nd }}$ Stage: Use of Adhesion Enhancing Agents}

The primer containing the HEMA monomer is applied to the surface of the enamel/dentin, where the surface conditions have been changed, in order to increase the surface energy due to its wettability. Instead of HEMA, many monomers are also used as primers. The primer molecules are bipolar and contain two different functional groups. Of these, the hydrophilic one interacts with moist dentin, while the hydrophobic one interacts with adhesives. Primers are binding-enhancing materials that dissolve in solvents such as water, ethanol, or acetone (23).

The primer is applied to the dentin surface with a microbrush until a bright surface is obtained in two or more layers according to the case after the roughening stage with acid, and dried with air for 5-10 seconds. During the drying process, care is taken to fully vaporize the solvents (acetone, ethanol) in the adhesive content. The primer prepares the surface for adhesive bonding by altering the sequences of collagen fibrils, and then helps make the penetration of the monomer more effective. The primer, which passes through the residual smear base in the acidified dentin tissue, is replaced by water on the dentin surface due to the volatile property of acetone and/or ethanol and fills the nano-cavities left by hydroxyapatite crystals that melt between the collagen fibrils.

\section{$3^{\text {rd }}$ Stage: Infiltration of Bonding Agent to Demineralized Enamel/Dentin Surface}

Bonding agents attached to enamel/dentin and resin are applied to enamel/dentin surfaces where surface conditions have been changed by acidification and then primer has been applied. Resin tags formed between the outer surfaces of enamel prisms as a result of penetration of bonding agents into interprismatic spaces are called "macrotag", while many resin tags formed in the form of network by penetration into intraprismatic spaces are called "mikrotag" $(25,26)$. Macro and microtags are responsible for micromechanical bonding in enamel tissue. Due to having large number and width of the fields of touch, the contribution of microtags to bonding is greater than that of macrotags. As a result of the studies, acceptable tag length is determined as
$10-30 \mu \mathrm{m}$ and it is shown that longer tags can break from the neck regions and tag length does not have an important role in bonding (27). After the primer applied, bonding agent is applied to the surface with a microbrush, a thin film layer is created by gently squeezing air and then it is polymerized. Thus, the hybrid layer formed after the primer application is polymerized with the binding agent.

Three-stage etch\&rinse (ER) adhesive systems (fourth generation) are still recognized as the gold standard. However, these systems can be time consuming because they require multiple application steps and technical precision. Due to the difficulty of the process steps, clinicians have begun to demand more simple and technical precision-free adhesive systems (18).

\section{Fifth Generation: Two-stage Etch\&Rinse Adhesive Systems}

By switching from three-stage systems to two-stage systems, the practice was simplified and began to be widely used by clinicians. In two-stage ER adhesive systems; following the stage of changing surface conditions of enamel/dentin (1. stage), the primer and bonding agent (adhesive resin) application stages (2. and 3 . stage) are combined, hydrophilic and hydrophobic monomers are collected in the same bottle (2. stage). The binding strength values of enamel tissue $(35-45 \mathrm{MPa})$ are the same as the threestage adhesive systems, but the binding strength values of dentin tissue (30-35 Mpa) are found to be lower than enamel (28).

In two-stage ERadhesive systems, in the first stage,enameland dentin tissues (30 seconds) (15 seconds) are simultaneously roughened with $30-40 \%$ orthophosphoric acid (total-etch) for 30 and 15 seconds, respectively and then washed with water. While the enamel is air-dried (15-10 seconds) until a matte image is obtained, excessive moisture on the dentin surface is taken with mild air squeezing (15-10 seconds) or a dry cotton pellet (2-5 seconds) to create moist dentin.In the second stage, primer and bonding (adhesive) agent,combined in a single bottle,are applied in two or more layersdepending on the casewith a brush until a bright surface is obtained. Then, by squeezing light air (5-10 seconds), a thin layer is formed and it is spread to the cavity. Then, the polymerization is carried out. Moist dentin tissue is important in terms of moist attachment strength (29). When the demineralized dentin tissue is over-dried, the water supporting the collagen fibrils evaporates and shrinkage occurs about $1 / 3$ of the original volume of the collagen web. There is a contraction in the spaces between the fibers, and then the formation of the hybrid layer is prevented. In the studies, it was determined that the binding strengths of acetone based adhesive systems were affected by the amount of moisture on the dentin surface (23).

Today, polyalcenoic acid in the primer forms a bond with calcium in the dentin tissue and the presence of moisture facilitates ion exchange. It was determined that moisture provides flexibility by reducing the increased elasticity modules value of collagen fibers after acidification, that moisture supports collagen fibers, and that moisture facilitates the infiltration of the monomer by widening the nanoscale gaps between fibers.In moist bonding, the dentin surface is washed (10-15 seconds) after being roughened with acid ( 15 seconds), the excess moisture on 
the surface is removed with mild air squeezing (5-10 seconds) or a dry cotton pellet (2-5seconds). Re-wetting of over-dried dentin ensures that the shrunken Type 1 collagen returns to its former volume. As a result, the collagen network expands. Instead of an over-wer (over-wet-20 pL) or over-dry (over-dry- $4 \mathrm{pL}$ ) dentine surface, a uniform glossy dentine surface is a clinically accepted moist dentin surface (4).

Sixth and seventh generation adhesive systems: SE adhesive systems (Adhesive systems that solve the smear layer)

\section{Sixth Generation: Two-stage Self-etch Adhesive Systems}

In this system, adhesiveand acidic primer are applied in two separate stages. In the first stage,after weakly acidic primer is applied intwo layers to dentin covered with smear layer, it is waited for the solute smear layer to join the binding and for adequate penetration of the primer into the intercollogenous cavities. After making it spread into the cavity by squeezing mildair, it is polymerized with a light source. If necessary, this process can be repeated several times in accordance with the recommendations of the manufacturer. In the second stage, the primer is polymerized with light by applying adhesives to the applied surfaces.

SE adhesive systems have been developed to protect the dentin and pulp tissue of the smear layer against bacterial irritation, to reduce fluid movements in the tubules and dentin permeability. Therefore, the working principle of SE adhesive systems is based not on removing the smear layer but on solving this layer.In these systems, the absence of roughening with separate acid, washing and drying processes found in ER adhesive systems reduces the stages of clinical application and saves clinicians' time. In this system; wet-bonding method is not applied and this system is not sensitive to changes in dentin moisture (over-wet, over-dry) thus, the possibility of error during the application decreases (4).

Weakly acidic primers used in SE adhesive systems are classified as ultra-light ( $\mathrm{pH}>2.5)$, light $(\mathrm{pH} \geq 2)$, medium $(\mathrm{pH} \sim 1.5)$ and strong $(\mathrm{pH} \geq 1) \mathrm{SE}$ adhesives according to their $\mathrm{pH}$ (30). They cause minimal dissolution of the smear tags without eliminating the smear layer and partially demineralize the dentin tissue, allowing the monomer to infiltrate the dentine. SE adhesive systems do not produce as effective roughening of enamel as ER adhesives. For this reason, it is recommended to apply acid to enamel to increase the binding with enamel (31).

The thickness of the hybrid layer formed in these systems, which is not affected by regional differences and pulpal pressures, is thinner than the thickness of the hybrid layer formed by ER Adhesive Systems (0.5-1.5 $\mu \mathrm{m}$ ) but the layer formed is uniform in structure. The adhesion mechanism is based on "hybridization", in which a uniform hybrid layer is formed intertwined with the smear layer. The upper part of the hybrid layer, in other words, hybridized smear layer, is formed as a result of infiltrationof resin monomers into the demineralized smear layer. The lower part of the hybrid layer, which is a real hybrid layer and is thinner isformed as a result of infiltrationof resin monomers into the collagen network (23).
Although SE adhesive systems form a thinner hybrid layer than total-etch systems, it has been reported that some of the monomers in their content make chemical bonding with the remaining hydroxyapatite crystals thus, these systems have good attachment strength (11).Because these systems do not completely eliminate the smear layer containing bacteria they may contain MDPB-12-methacryloyloxydode cylpridinium bromide, a quaternary ammonium analogue, which shows a strong antibacterial activity against to bacteria in the mouth, especially to $S$. Mutans andwhich also continues its effect after polymerization (32).

\section{Seventh Generation: Single Stage Self-etch Adhesive Systems}

Self etch adhesive materials that combine acid, primary and bonding steps in a solution, without washing and with reduced clinical application stages are gaining increasing popularity. The reduction of stages has made this system an easier system for physicians (33). Whereas there is a mixing process prior to application in type 1 single-stage adhesive systems with two-components, the mixing process is not necessary in type 2 single-stage (all-in-one) adhesive systems with one component (34). Compared to classical adhesive systems, single-stage adhesive systems contain non-polymerized ionic monomers that come in direct contact with the composite (35).This unreacted acidic monomers are partly responsible for the mismatch between single-stage adhesive systems with self-cure composites (35). Furthermore, these systems tend to act as semipermeable membranes (34), resulting in hydrolytic degradation of the resin-dentin interface (36). These adhesives usually contain resin monomers with organophosphate and carboxylate structure, as they have to have sufficient acidity to demineralize the enamel and dissolve the smear layer (37). They also contain highly acidic hydrophilic monomers and water ( 5 to $50 \%$ ) which allows acidic monomers to be ionized.However, due to their content, they are prone to hydrolysis, hydrolytic degradation and chemical degradation $(33,36)$. The permeability of polymerized adhesive allows water passage from the dentin, creating water bubbles along the composite-adhesive interface that cause hydrolytic degradation (34). Water bubbles are an indication of free water that has not evaporated sufficiently, remaining in the adhesive which is not polymerized during the drying process. Tay and Pashley indicated that these microscopic formations, which Sano et al. (37) first showed in regions where there is not fully resin infiltration before polymerization, are masses of water in the view of the water tree, clinging to adhesive-dentin interface, which vary depending on the ionic structure, hydrophilicity and thickness of adhesive (38). The TEM (Transmission Electron microscopy) microscope showed that these masses of water starting from the hybrid layer and reaching the adhesive-composite interface, allowing the movement of water in the adesiv and hybrid layer, causing nanoleakage formation,formed spotted or reticular images (39). Water masses form obstacles for the polymerization reaction and for completion of hydrogel formation of the HEMA in the adhesive content (38). No such problems are encountered in two-stage $\mathrm{SE}$ adhesives, which are less permeable and more hydrophobic than single-stage SE adhesives (23). 


\section{Eighth Generation Adhesive Systems}

Eighth generation adhesive systems containing nanoscale particles were first introduced in 2010 (36). These systems have single component and have nano fillers with an average particle size of $12 \mathrm{~nm}$ in their structure. These nano fillers increase the thickness of the hybrid layer which improves the penetration of resin monomers and the mechanical properties of adhesive systems $(31,40)$. Nano-binding agents are nano-filling solutions with a longer shelf life, which demonstrate better enamel and dentin binding strength and stress absorption (17). Acidic hydrophilic monomers are involved in the structure of eighth generation adhesive systems. The main advantages of these systems are that they can be easily applied to acidified enamel surface even if they are subsequently contaminated with saliva or moisture (41). The manufacturer claims that nanoparticles acting as crucibles will reduce dimensional changes $(42,43)$. The type and manner in which nano fillers are incorporated into the structure affect the viscosity of the adhesive and the ability of resin monomers to penetrate collagen fiber cavities. With dimensions greater than $15-20 \mathrm{~nm}$ or with content greater than $1.0 \%$ by weight, these systems can increase the viscosity of adhesives. It can also result in clustering of fillers on the moist surface. These clusters can cause cracks and decrease in binding force (43).

\section{Universal (Multi-mode) Adhesive Systems}

Universal adhesives have been used in clinics since 2011. These systems are also known as multi-mode or multi-purpose adhesives. Because these adhesive systems can be used as SE adhesives, the ER adhesives or SE adhesives in dentin tissue and ER adhesives on enamel tissue (a technique known as selective acidification of enamel) $(31,40,44)$. These systems, enabling the implementation of the total-etch or selective-etch approaches, have been developed to improve weakness of the previous generation single-step SE adhesives and to obtain a strong bonding in enamel tissue. As a result of the studies, it was revealed that good results were obtained regarding the binding strengths of universal adhesives $(31,45)$.

The majority of universal adhesives are designed based on the all-in-one concept of existing single-stage SE adhesives. Water is needed to ionize hydrophilic acidic monomers in formulations of these new adhesive systems (31). The $\mathrm{pH}$ value of current universal adhesives varies between 2.2 and 3.2, although it varies by product $(46,47)$. There is a concern that universal adhesives in this $\mathrm{pH}$ range may be very effective when evaluated for attachment with dentin tissue, but they may not be effective when it comes to attachment to enamel tissue, especially to prepared enamel $(36,48)$. Universal adhesives have, in fact, similar content with conventional single-stage SE adhesives and contain carboxylate or phosphate monomer that binds to calcium in hydroxyapatite. Monomers such as methacryloyloxydecyl dihydrogen phosphate (10-MDP), silane, polyacrylic acid are often added to their structures. 10-MDP monomer is included in universal adhesive systems due to its chemical binding to hydroxyapatite, which exists in both mine and dentin tissue (11). Additionally, these systems include BPDM, PENTA (49) and polyalkenoic acid copolymers which can increase attachment to dental tissues $(50,51)$. Furthermore, the matrix structure of universal adhesive systems consists of a combination of hydrophilic HEMA, hydrophobic UDMA and Bis-GMA monomers. As a result of the combination of these properties, universal adhesives provide a bridge between hydrophilic dental tissue and hydrophobic composite resin under various surface conditions. Silane, which is included in the formulations of universal adhesives, eliminates silanization during the binding phase of composite resins to glass ceramics (17). The multifaceted uses of these systems primarily include the advantages of the traditional ER technique. In addition, clinicians using this bonding system have the opportunity to apply both selective etch and SE techniques. Therefore, universal adhesives have a much wider application area than $7^{\text {th }}$ generation dentin bonding systems. In addition, the manufacturer states that universal adhesives can be used for the application of both direct and indirect restorations, and they are also compatible with self-cure, light-cure and dual-cure resinbased simans, metal, zirconia, porcelain and composites (18). However, the main disadvantage of universal adhesives is that they contain water like other single stage SE adhesives, resulting in hydrolytic destruction. Therefore, it is recommended to apply hydrophobic resin on the polymerized universal adhesive. Since the presence of water is a problem for all single-stage adhesives, ethanol is being studied (31).

\section{Glass İonomer Based Adhesives}

These systems are resin-modified glass ionomer adhesives that connect resin composites to dental tissue as a result of combining resin and glass ionomer technology. Glass ionomer material is the only self-adhesive material that can hold on to the tooth tissue without any surface treatment (15).

\section{Places Where Adhesive Systems are used in Dentistry}

a) In composite restorations,

b) In compomer (Dyract) restorations,

c) In adhesion of indirect restorations

d) As cavity varnish under Amalgam restorations,

e) In the protection of root surfaces revealed after gingival removal and removal of dentin sensitivity,

f) In repair of crown-bridge restorations obtained from Porcelain, hybrid ceramic, and composite materials in the mouth and in the construction of core together with composites polymerized by light or dual-cure.

\section{Properties of Adhesive Systems that are Widely used in Dentistry Clinical Applications}

a. They should be biocompatible and should not damage the pulp tissue of the tooth in particular,

b. They should be able to connect micromechanically and chemically to hard tissues of teeth (enamel and dentin),

c. Apart from the hard tissues of the teeth, they should also be connected to metal and porcelain,

d. They should prevent post-treatment sensitivity by blocking all/ most of the dentin channels, 
e. Be able to resist the stresses caused by mastication forces and polymerization shrinkage stresses,

f. They must be resistant to thermal expansion and thermal shrinkage,

g. Should be able to apply easily on moist surfaces,

h. They must be resistant to microleakage and prevent secondary caries,

i. Shelf life should not be short,

j. Clinical applications should not be difficult and application steps should be reduced,

k. The film thickness should be minimum (less than $20 \mu \mathrm{m})(18)$.

\section{Conclusion}

Safe bonding of composite resins to enamel and dentin tissues via adhesive systems allows more conservative cavity preparation instead of cavity prepared for amalgam restorations in operative dentistry. Advances in dentin bonding systems and application techniques make it possible for these systems to be used in many other areas of Dentistry. However, even if better and easier-to-use materials are produced, the clinician must first pay attention to the technique during the application in order to make a successful restoration in the clinic. However, it is also very important that bonding is done under ideal conditions.

The current concept of minimally invasive dentistry has led to a significant development in dental adhesiv technology. The Etch \& rinse approach, especially in cases where the enamel is more dominant than the dentin tissue, in other words, in cases in whom a better adhesion on the front teeth is wanted, can be more appropriate. In posterior teeth, active application of 10MDP based two-stage SE adhesive systems to both enamel and dentin tissue following selective etch process in enamel with phosphoric acid, can be considered a good strategy for achieving optimal restoration durability.

With the new adhesive systems, successful results are achieved in reducing or eliminating sensitivity after restoration, reducing micro leakages and ensuring that the resin can be spread nicely to the tooth tissues. Therefore, the success of adhesive materials in in vitro should be supported by clinical follow-up to evaluate the long-term durability of composite materials within the mouth.

Peer-review: Externally peer-reviewed.

Conflict of Interest: No conflict of interest was declared by the authors.

Financial Disclosure: The authors declared that this study received no financial support.

\section{References}

1. Buonocore MG. A simple method of increasing the adhesion of acrylic filling materials to enamel surfaces. J Dent Res 1955;34:849-53.
2. Nakabayashi N. Resin reinforced dentin due to infiltration of monomers into the dentin at the adhesive interface. JSDMD 1982;1:78-81.

3. Van Meerbeek B, Inokoshi S, Braem M, Lambrechts P, Vanherle G. Morphological aspects of the resin-dentin interdiffusion zone with different dentin adhesive systems. J Dent Res 1992;71:1530-40.

4. Dayangac B. Bonding sistemleri "Kompozit rezin restorasyonlar". Ankara: Gunes Kitabevi Ltd. Sti; 2000.

5. The Physics of Adhesives [Internet]. Available from: URL: http:// ffden-2.phys.uaf.edu.

6. Rosa AJ, da Silva EM, Tostes MA. Scanning electron microscopy analysis of microstructure of the adhesive interface between resin and dentin treated with papain gel. Indian J Dent Res 2015;26:77-81.

7. Schwartz RS, Summit JB, Robbins W. Fundamentals of Operative Dentistry. USA: Quintessence Publishing Co, Inc.; 1996.p.141-86.

8. Fukushima $\mathrm{T}$, Inoue $\mathrm{Y}$, Miyazaki $\mathrm{K}$, Itoh $\mathrm{T}$. Effect of primers containing $\mathrm{N}$-methylolacrylamide or $\mathrm{N}$-metyklolmethacrylamide on dentin bond durability of a resin composite after 5 years. J Dent 2001;29:227-34.

9. Breschi L, Mazzoni A, De Stefano D, Ferrari M. Adhesion to intraradicular dentin: A review. J Adhes Sci Technol 2009;7:1053-83.

10. Sideridou I, Tserki V, Papanastasiou G. Study of water sorption, solubility and modulus of elasticity of light-cured dimethacrylatebased dental resins. Biomaterials 2003;24:655-65.

11. Van Landuyt KL, Snauwaert J, De Munck J, Peumans M, Yoshida Y, Poitevin A, et al. Systematic review of the chemical composition of contemporary dental adhesives. Biomaterials 2007;28:3757-85.

12. Nakabayashi N, Kojima K, Masuhara E. The promotion of adhesion by the infiltration of monomers into tooth substrates. J Biomed Mater Res 1982;16:265-73.

13. Youngson CC, Gray NJ. An in vitro comparative analysis: Scanning electron microscopy of dentin/restoration interfaces. Dent Mater 1992;8:252-58.

14. Erickson RL. Surface interactions of dentin adhesive materials. Oper Dent 1992;5:81-94.

15. Heymann HO, Swift EJ, Ritter AV, editors. Sturdevant's Art \& Science of Operative Dentistry-E-Book. 6th ed. Mosby: Elsevier, Chapter 4;2013.

16. Joseph P, Yadav C, Satheesh K, Rahna R. Comparative evaluation of the bonding efficacy of sixth, seventh and eight generation bonding agents: An in vitro study. IRJP 2013;4:143-7.

17. Sofan E, Sofan A, Palaia G, Tenore G, Romeo U, Migliau G. Classification review of dental adhesive systems: From the IV generation to the universal type. Ann Stomatol 2017;8:1-17.

18. Van Meerbeek B, Perdigao J, Lambrechts P, Vanherle G. The clinical performance of adhesives. J Dent 1998;26:1-20.

19. Latta M, Barkmeier WW. Dental adhesives in contemporary restorative dentistry. Dent Clin North Am 1998;42:567-77.

20. Kugel G, Ferrari M. The science of bonding: From first to sixth generation. JADA 2000;127:20-5.

21. Bowen RL, Rodriguez MS. Tensile strength and modulus of elasticity of tooth structure and several restorative materials. JADA 1962;64:378-87. 
22. Perdigão J. An ultra-morphological study of human dentine exposed to adhesive systems [thesis]. Leuven KUL: Van der Poorten; 1995.

23. Fusayama T, Nakamura M, Kurosaki N, Iwaku M. Non-pressure adhesion of a new adhesive resin. J Dent Res 1979;58:1364-70.

24. Silverstone LM, Saxton CA, Dogon IL, Fejerskov O. Variation in the pattern of acid etching of human dental enamel examined by scanning electron microscopy. Caries Res 1975;9:373-87.

25. Tyas MJ, Burrow MF. Adhesive restorative materials: A review. Aust Dent J 2004;49:112-21.

26. Wagner A, Wendler M, Petschelt A, Belli R, Lohbauer U. Bonding performance of universal adhesives in different etching modes. J Dent 2014; $42: 800-7$.

27. Van Meerbeek B, Inokoshi S, Braem M, Lambrechts P, Vanherle G. Morphological aspects of the resin-dentin interdiffusion zone with different dentin adhesive systems, J Dent Res 1992;71:1530-40.

28. Van Meerbeek B, De Munck J, Mattar D, Van Landuyt K, Lambrechts P. Microtensile bond strengths of an etch and rinse and self-etch adhesive to enamel and dentin as a function of surface treatment. Oper Dent 2003;28:647-60.

29. Ahn J, Jung KH, Son SA, Hur B, Kwon YH, Park JK. Effect of additional etching and ethanol-wet bonding on the dentin bond strength of one-step self-etch adhesives. Rest Dent Endod 2015;40:68-74.

30. Güven Y, Aktören O. Adezif sistemlerin yapısal özelliklerinin adezif sistem-diş yüzeyi bağlantısındaki rolü. İÜDHFD Derleme 2014; $48: 57-65$.

31. Hanabusa M, Mine A, Kuboki T, Momoi Y, Van Ende A, Van Meerbeek B, et al. Bonding effectiveness of a new "multi-mode" adhesive to enamel and dentine. J Dent 2012;40:475-84.

32. Imazato $S$. Antibacterial adhesive system - The potential benefit to successful restoration. In: Sano H, Uno S, Inoue S, editors. Modern Trends in Adhesive Dentistry Proceedings of the Adhesive Dentistry. Dental Material Department, Medical Products Division, Kuraray Co, Ltd; Japan: 1998.p.107-14.

33. Nishiyama N, Tay FR, Fujita K, Pashley DH, Ikemura K, Hiraishi $\mathrm{N}$, et al. Hydrolysis of functional monomers in single-bottle selfetching primer-correlation of 13C NMR and TEM findings. J Dent Res 2006;85:422-6.

34. Tay FR, Pashley DH, Suh BI, Carvalho RM, Itthagarun A. Single step adhesives are permeable membranes. J Dent 2002;30:371-82.

35. Tay FR, Pashley DH, Peters MC. Adhesive permeability affects composite coupling to dentin treated with a self-etch adhesive. Oper Dent 2003;28:610-21.
36. Tay FR, Pashley DH. Aggressiveness of contemporary self-etching systems. I: Depth of penetration beyond dentin smear layers. Dent Mater 2001;17:296-308.

37. Sano H, Yoshikawa T, Pereira PN, Kanemura N, Morigami M, Tagami J, et al. Long-term durability of dentin bonds made with a self-etching primer, in vivo. J Dent Res 1999;78:906-11.

38. Tay FR, Pashley DH. Water treeing-A potential mechanism for degradation of dentin adhesives. Am J Dent 2003;16:6-12.

39. Donmez N, Belli S, Pashley DH, Tay FR. Ultrastructural correlates of in vivo/in vitro bond degradation in self-etch adhesives. J Dent Res 2005;84:355-9.

40. Perdigao J, Sezinando A, Monteiro PC. Laboratory bonding ability of a multi-purpose dentin adhesive. Am J Dent 2012;25:153-8.

41. Karami Nogourani M, Javadi Nejad Sh, Homayunzadeh M. Sealant Microleakage in saliva-contaminated enamel: Comparison between three adhesive systems. J Dent Sch 2010;27:197-204.

42. Basaran G, Ozer T, Devecioğlu Kama J. Comparison of a recently developed nanofiller self-etching primer adhesive with other selfetching primers and conventional acid etching. Eur J Orthod 2009;31:271-5.

43. Kasraei SH, Atai M, Khamverdi Z, Khalegh Nejad S. Effect of nanofiller addition to an experimental dentin adhesive on microtensile bond strength to human dentin. J Dent (Tehran) 2009;6:91-6.

44. Munoz MA, Luque-Martinez I, Malaquias P, Hass V, Reis A, Campanha $\mathrm{NH}$, et al. In vitro longevity of bonding properties of universal adhesives to dentin. Oper Dent 2015;40:282-92.

45. Sezinando A. Looking for the ideal adhesive-A review. Rev Port Estomatol Cir Maxilofac 2014;55:194-206.

46. Van Meerbeek B, Yoshihara K, Yoshida Y, Mine A, De Munck J, Van Landuyt KL. State of the art of selfetch adhesives. Dent Mater 2011;27:17-28.

47. Perdigao J, Lopes L, Lambrechts P, Leitâo J, Van Meerbeek B, Vanherle G. Effects of a self-etching primer on enamel shear bond strengths and SEM morphology. Am J Dent 1997;10:141-6.

48. Miyazaki M, Sato M, Onose H. Durability of enamel bond strength of simplified bonding systems. Oper Dent 2000;25:75-80.

49. De Munck J, Van Meerbeek B, Yoshida Y, Inoue S, Vargas M, Suzuki K, Lambrechts P, Vanherle G. Four-year water degradation of totaletch adhesives bonded to dentin. J Dent Res 2003;82:136-40.

50. Hashimoto M, Ito S, Tay FR, Svizero NR, Sano H, Kaga M, et al. Fluid movement across the resin-dentin interface during and after bonding. J Dent Res 2004;83:843-48. 